\title{
A Clinicopathological \& Radiological Evaluation Of Scrotal Swellings
}

\author{
Dr. Anchal Chauhan ${ }^{1}$,Dr Shashank Mishra ${ }^{2}$, Dr. Prof. Ghulam Jeelani ${ }^{3}$, \\ ${ }^{I}$ Junior Resident III PG Dept Of Surgery Subharti Medical College, Meerut (*Corresponding Author) \\ ${ }^{2}$ Associate Professor PG Dept Of Surgery Subharti Medical College, Meerut \\ ${ }^{3}$ Professor PG Dept Of Surgery Subharti Medical College, Meerut
}

\begin{abstract}
Scrotal swellings were earlier considered to be an area over unaided clinical expertise. Scrotal swelling can occur in males at any age. Scrotal masses may be intratesticular or extratesticular, either solid or cystic.A prospective study was done on 50 patients presenting to our hospital over 1 years with complaint of scrotal swelling. Factors such as age, presenting complaint, laterality were analysed, a definite diagnosis was made on the basis of USG, Colour Doppler and Histology. Collected data was then analysed and compared to previous studies.
\end{abstract}

Keywords: scrotal swellings, ultrasonography scrotum

\section{Introduction}

The scrotum was earlier considered as an area of unaided clinical expertise. Nevertheless, the nature of some of the scrotal masses remains baffling. Scrotal swelling is an abnormal enlargement of the scrotum. This is the name for the sac surrounding the testicles. ${ }^{1}$ Scrotal masses may be intratesticular or extratesticular, either solid or cystic. Most of the intratesticular masses should be considered malignant unless proven otherwise. Extratesticular cystic masses are almost certainly benign. Common causes of scrotal swelling include epididmytis, hydrocele, varicocele.

Although testicular tumours are rare, accounting for fewer than 1 per cent of all cancers, they are the most common solid tumours to affect young men aged 15-44 years, with 1871 cases in England in 2010. ${ }^{2}$ Testicular tumours are treatable, with 97 per cent overall five-year survival. ${ }^{3}$ Risk factors for testicular tumours include age, Caucasian ethnicity, cryptorchidism, family history, a history of testicular tumour in the contralateral testism. HIV infection, Down syndrome, and testicular trauma. ${ }^{4}$

Presentation of testicular tumors may be with a painless unilateral lump within the testis with symptoms mimicking epididymo-orchitis and gynaecomastia.

Accurate diagnosis of scrotal swellings is of paramount importance, since they may range from the common ones, hydrocele (Commonest), and rare ones like malignancy causing secondary hydrocele, hematocele, pyocele. Clinical examination is often elucidative in scrotal diseases and therefore imaging is not frequently required. When necessary, ultrasonography (US) is the first option and often, the only imaging method required to make a reliable diagnosis, ${ }^{5,6,7,8}$ because of its good accuracy and availability and the anatomic details provided by high frequency, linear transducers. ${ }^{9}$ The ability of Color Doppler to study blood flow ${ }^{10}$ makes US an excellent imaging method in acute scrotal diseases. ${ }^{11}$

The main aim of our study was to determine various etiological aspects of different swellings of scrotum, along with various modes of presentations and its management.

\section{Material And Methods}

A prospective study was conducted during October 2015- September 2016 on patients admitted with complaints of scrotal swellings sample size was 50 patients $(n=50)$. Patients were informed of this study and a written consent was taken from all patients who were willing for participation.A diagnosis was made on the basis of history, clinical examination, laboratory and radiological investigations.

\section{Procedure}

Each patient gave written, informed consent to participate in this study and the study protocol was approved by the institutional review board including ethical issue. A detailed history and examination of each patient was done. Lab investigations such as Complete Blood Count, Random Blood Sugar, Blood Urea, Serum Creatinine.,Urine Routine microscopy, Urine culture and sensitivity, Ultrasonography of scrotum, Colour Doppler of Scrotum and if required histology was also done depending upon the case. Definite management was done after confirming the diagnosis on the basis of above investigations and patients were managed on the basis of each and every individual case. 


\section{Observation And Results}

Table 1: Age Wise Distribution

\begin{tabular}{ccc}
\hline Age Group & No. of Cases & Percentage \\
\hline $\mathbf{0 - 1 0}$ & 1 & $2 \%$ \\
\hline $\mathbf{1 1 - 2 0}$ & 8 & $16 \%$ \\
\hline $\mathbf{2 1 - 3 0}$ & 20 & $40 \%$ \\
\hline $\mathbf{3 1 - 4 0}$ & 9 & $18 \%$ \\
\hline $\mathbf{4 1 - 5 0}$ & 7 & $14 \%$ \\
\hline $\mathbf{5 1 - 6 0}$ & 2 & $4 \%$ \\
\hline $\mathbf{6 1 - 7 0}$ & 1 & $2 \%$ \\
\hline $\mathbf{7 1 - 8 0}$ & 2 & $4 \%$ \\
\hline Total Patients & $\mathbf{5 0}$ & $\mathbf{1 0 0 \%}$
\end{tabular}

Table 2: Distribution Of Cases According To Laterality Of Scrotal Swelling

\begin{tabular}{ccc}
\hline Laterality & No of Cases & Percentage \\
Right & 15 & $30 \%$ \\
\hline Left & 22 & $44 \%$ \\
\hline Bilateral & 13 & $26 \%$ \\
Total & $\mathbf{5 0}$ & $\mathbf{1 0 0 \%}$
\end{tabular}

Table 3: Diagnosis on the basis of Ultrasonography

\begin{tabular}{lcc}
\multicolumn{1}{c}{ Radiological Diagnosis } & No of Cases & Percentage \\
Acute epididymitis & 7 & $14 \%$ \\
\hline Acute epididmo-orchits & 3 & $6 \%$ \\
\hline Scrotal abscess & 2 & $4 \%$ \\
\hline Hematocele & 1 & $2 \%$ \\
\hline Hydrocele & 20 & $40 \%$ \\
\hline Epididymal Cyst & 3 & $6 \%$ \\
\hline Spermatocele & 1 & $2 \%$ \\
\hline Varicocele & 10 & $20 \%$ \\
\hline Testicular torsion & 1 & $2 \%$ \\
\hline Testicular neoplasm & 2 & $4 \%$ \\
\hline \multicolumn{1}{r}{ Total } & $\mathbf{5 0}$ & $\mathbf{1 0 0 \%}$
\end{tabular}

Table 4: Distribution of cases according to Treatment Modalities

\begin{tabular}{|c|c|c|}
\hline Treatment & No of Cases & Percentage \\
\hline Conservative & 14 & $28 \%$ \\
\hline Eversion Of Sac & 16 & $32 \%$ \\
\hline Varicocelectomy & 6 & $12 \%$ \\
\hline $\begin{array}{l}\text { I And D } \\
\text { (Incision and drainage) }\end{array}$ & 3 & $6 \%$ \\
\hline Conservative Followed By Eversion Of Sac & 4 & $8 \%$ \\
\hline Conservative Followed By Varicocelectomy & 2 & $4 \%$ \\
\hline Detorsion With Orchidopexy & 2 & $4 \%$ \\
\hline Eversion Of Sac And Varicocelectomy & 1 & $2 \%$ \\
\hline High Inguinal Orchidectomy & 2 & $4 \%$ \\
\hline Total & 50 & $100 \%$ \\
\hline
\end{tabular}

Table 5: Distribution of cases according to Urine Culture examination

\begin{tabular}{ccc}
\hline Organism & No of Cases & Percentage \\
No growth & 35 & $70 \%$ \\
\hline E. Coli & 6 & $12 \%$ \\
\hline Enterococcus & 3 & $6 \%$ \\
\hline Klesiella Pnemoniae & 5 & $10 \%$ \\
\hline Proteus & 1 & $2 \%$ \\
\hline Total Cases & $\mathbf{5 0}$ & $\mathbf{1 0 0 \%}$
\end{tabular}




\section{Results}

Out of the total 50 patients included in this study the maximum incidence of patients were in the 21-30 years of age group (Table-1) Left side was more common which was seen in $44 \%$ cases (Table-2). Most common diagnosed on the basis of USG was hydrocele.(Table-3) $4 \%$ of patients were diagnosed with neoplasm (seminoma) that underwent high inguinal orchidectomy. (Table-4) Most common organism found on urine culture and sensitivity analysis was E.Coli in $12 \%$ of cases (Table 5) but maximum patients had no growth seen in their urine culture and sensitivity.

\section{Discussion}

Tumors are the major pathological lesion in the testis. Testicular cancer is the most general solid tumor of young men but only accountable for about $1 \%$ of all cancers in men. ${ }^{12}$ Epidemiological risk factors for the development of testicular tumours include: a history of cryptorchidism, Klinefelter's syndrome, a familial history of testicular tumours among first-degree relatives (father or brothers), the presence of a contralateral tumour, and infertility. ${ }^{13,14,15}$ Trauma, hormones such as diethylstilboestrol, and non-specific mumps-associated testicular atrophy have also been implicated as risk factors.

Laterality of scrotal swelling revealed that in our study $44 \%$ of cases were having swelling in left side whereas $30 \%$ at right side while $26 \%$ were having bilateral scrotal pain. These findings were comparable to findings of Patel et $\mathrm{al}^{16}$ and with other multiple studies ${ }^{17,18,19}$. USG findings in our setting revealed Hydrocele as most prominent cause of scrotal swellings i.e. $40 \%$, followed by Varicocele $20 \%$, acute epididymitis $14 \%$, Acute epididmo-orchits $6 \%$. Testicular neoplasm was diagnosed as $4 \%$ of the studied cases. Management of cases was done with different treatment modalities, $28 \%$ patients who were treated conservatively, Eversion of Sac for hydrocele was practiced in $32 \%$ patients, and Varicocelectomy for varicocele in $12 \%$ of patients, Incision and drainage procedure was put into practice for $6 \%$ of patients suffering from scrotal abscess whereas Conservative means followed by Eversion of Sac in $8 \%$ of patients and Conservative Management followed by Varicocelectomy in $4 \%$ of patients, Detorsion with Orchidopexy in $4 \%$ of patients and High Inguinal Orchidectomy in $4 \%$ of patients, and Eversion of Sac with Varicocelectomy 2\% patients. Testicular Mass was viable in $4 \%$ of the cases. And seminoma was the only type of testicular tumor which was found in our study.

\section{Conclusion}

The present study was done with a view to evaluate scrotal swellings in terms of their types, presentation and management modalities in 50 consecutive cases of scrotal swellings, a clinicopathological \& radiological evaluation. Accordingly an evaluation and management protocol was formulated by a master chart and the outcome was documented. Based on the observations and results of our research project over a period of 1 years (October 2015-September 2016), we concluded as follows. Ultrasonography was the most common and easily available modality for diagnosing scrotal swellings along with prompt clinical examination followed by appropriate surgical/medical management. The most prominent site of involvement of scrotal swelling encountered in our setting was epididymis in $44 \%$ cases followed by pampiniform plexus in $24 \%$, testis in $16 \%$ and spermatic cord was in $12 \%$ cases. Most common diagnosis was Hydrocele whereas testicular neoplasm was seen in $4 \%$ of cases. Urine Culture showed E.Coli as the most common organism i.e. in $12 \%$ cases of acute epididmo-orchits as a case of scrotal swelling.

In the management of 100 cases of scrotal swellings in the present series $28 \%$ cases were treated conservatively (antibiotics, scrotal support, analgesics, etc), $32 \%$ patients underwent eversion of sac(Jaboleys Procedure), Varicocelectomy was done in case of $12 \%$ patients, I And D (Incision and drainage) procedure was put into practice in $6 \%$ patients. Conservative means(antibiotics, scrotal support, analgesics, etc) followed by Eversion of Sac in $8 \%$ patients with acute Epididymitis, acute epididmo-orchits along with hydrocele, Conservative management(antibiotics, scrotal support, analgesics, etc) with Varicocelectomy was done in $4 \%$ patients with acute Epididymitis, acute epididmo-orchits with varicocele, Detorsion with Orchidopexy was done in $4 \%$ patients, High inguinal Orchidectomy in $4 \%$ patients for testicular tumour. $4 \%$ of the patients coming with scrotal swellings were diagnosed as a case of testicular tumour (seminoma), the incidence of which almost matches the available data, as per the standard protocol they were treated with a high orchidectomy and are under follow up.

\section{References}

[1]. Singh AK. Clinico pathological Study of Cystic Swellings of Scrotum. Asian Journal of Biomedical and Pharmaceutical Sciences, 6(57), 2016, 42-44.

[2]. Office for National Statistics. Cancer statistics registrations, England, series MB1, no. 41, 2010, 2012

[3]. Office for National Statistics. Cancer survival in England - patients diagnosed 2005-2009 and followed up to $2010,2011$.

[4]. Garner MJ, Turner MC, Ghadirian P, Krewski D. Epidemiology of testicular cancer: an overview. Int J Cancer 2005; 116(3): 331-9.

[5]. Cramer BM, Schlegel EA, and Thueroff JW: MR imaging in the differential diagnosis of scrotal and testicular disease. Radiographics, 11, 1991, 9-21. 
[6]. Serra AD, Hricak H, Coakley FV: Inconclusive clinical and ultrasound evaluation of the scrotum: impact of magnetic resonance imaging on patient management and cost. Urology, 51, 1998, 1018-1021.

[7]. Thurnher S, Hricak H, Carrol PR: Imaging the testis: comparison between MR imaging and US. Radiology, 167, 1987, 631-636.

[8]. Fritzsche PJ, Hricak H, Kogan B: Undescended testis: value of MR imaging. Radiology, 164, 1987, 169-173

[9]. Rifkin M, Kurtz A, and Pasto ME: Diagnostic capabilities of high-resolution scrotal ultrasonography: prospective evaluation. J Ultrasound Med, 4, 1985, 13-19

[10]. Semba CP, Trambert MA, and Mattrey RF: Specificity of MR imaging in the evaluation of scrotal disease versus US (abstract). Radiology, 181 (suppl), 1991, 129.

[11]. Saman SS, Semba CP, and Mattrey RF: Should magnetic resonance imaging of the scrotum be used after sonography. AJR Am J Roentgenol, 157(suppl), 1991, 74-75

[12]. Office for National Statistics. Cancer Statistics Registrations: Registrations of Cancer Diagnosed in 2002 England. Series MB1 no.33. London: Office for National Statistics, 2005.

[13]. Sagalowsky AL: Current consideration in the diagnosis and initial treatment of testicular cancer. Compr Ther 1994, 20:688-690.

[14]. Daniels JL, Stutzman RE, Mcleod DG: Comparison of testicular tumors in black and white patients. J Urol 1981, 125:341-343.

[15]. Moller H: Trends in incidence of testicular cancer and prostate cancer in Denmark. Hum Reprod 2001, 16:1007-1011.

[16]. Patel MB, Goswami HM, Parikh UR, Mehta N. Histo-pathological study of testicular lesions. Gujrat Med J 2015;70(1):41-6.

[17]. Magoha GAO: Testicular cancer in Nigerians. East Afr Med J 1995, 72:554-556.

[18]. Opot EN, Magoha GA: Testicular cancer at Kenyatta National Hospital. Nairobi East Afr Med J 2000, 77:80-85.

[19]. Ugwumba FO, Aghaji AE: Testicular cancer: management challenges in an African developing country. S Afr Med J 2010, 100:452-455. 